\title{
Cooperativismo e desenvolvimento: aproximações acerca dos Objetivos de Desenvolvimento Sustentável (ODS)
}

O presente estudo tem como objetivo identificar como o cooperativismo permite uma aproximação e participa da construção do desenvolvimento sustentável, proporcionando a reflexão e sensibilização a respeito das oportunidades e desafios que os Objetivos de Desenvolvimento Sustentável (ODS) representam neste cenário. Metodologicamente, o estudo se classifica como uma pesquisa quali-quantitativa, fundamentada em um levantamento bibliográfico e documental de caráter exploratório, visto que o objetivo deste estudo é identificar como o cooperativismo participa da construção das condições para o desenvolvimento sustentável, em especial via Agenda 2030. A etapa qualitativa buscou identificar a relação existente entre os Princípios do Cooperativismo e os ODS, enquanto que a etapa quantitativa e buscou mensurar as ações de responsabilidade social que foram desenvolvidas pelas cooperativas brasileiras, vinculadas ao programa Dia de Cooperar (Dia C), e que contribuem direta ou indiretamente para o alcance dos ODS. As principais conclusões permitem afirmar que o cooperativismo está relacionado aos Objetivos de Desenvolvimento Sustentável em sua teoria e prática, tanto a partir dos princípios e valores que norteiam o movimento, em especia o da intercooperação e do interesse pela comunidade, quanto em se considerando as ações de responsabilidade socioambiental desempenhadas pelas cooperativas nos espaços onde estas se encontram. Entende-se assim, que o cooperativismo desempenha um papel fundamental na construção da mudança de paradigmas e comportamentos que conduzirão à construção do desenvolvimento sustentável.

Palavras-chave: Sustentabilidade; Objetivos de Desenvolvimento Sustentável; Cooperativismo.

\section{Cooperatives and development: approaches to the Sustainable Development Goals (SDGs)}

\begin{abstract}
The present study aims to identify how cooperativism allows an approach and participates in the construction of sustainable development, providing reflection and awareness about the opportunities and challenges that the Sustainable Development Goals (SDGs) represent in this scenario. Regarding the method, the study classifies as a qualitative and quantitative research, based on an exploratory, bibliographic and documentary survey, since the objective of this study was to identify how cooperativism participates in the construction of conditions for sustainable development, especially through the Agenda 2030. The qualitative stage sought to identify the relationship between the Principles of Cooperativism and the SDGs, while the quantitative stage sought to measure the social responsibility actions that were developed by Brazilian cooperatives, linked to the Cooperating Day program (Day C), which contribute directly or indirectly to the achievement of the SDGs. The main conclusions allow us to affirm that cooperativism is related to the Sustainable Development Goals in its theory and practice, both from the principles and values that guide the movement, especially from intercooperation and community interest, as well as from the actions taken through environmental and socia responsibility actions driven by the cooperatives in the spaces where these are located. Thus, it is understood that cooperativism plays a fundamental role in constructing the change of paradigms and behaviors that will lead to the construction of sustainable development.
\end{abstract}

Keywords: Sustainability; Sustainable Development Goals; Cooperativism.

Topic: Desenvolvimento, Sustentabilidade e Meio Ambiente

Reviewed anonymously in the process of blind peer.
Received: 03/03/2021

Approved: 26/03/2021
Bruno Nonnemacher Buttenbender (iD) Universidade do Vale do Taquari, Brasil http://orcid.org/0000-0001-9762-8977 brunonbuttenbender@gmail.com

\section{Douglas Henrique Flach (DD}

Universidade do Vale do Taquari, Brasil http://orcid.org/0000-0001-7650-3497 douglas.flach@univates.br

Carlos Cândido da Silva Cyrne (iD

Universidade do Vale do Taquari, Brasil http://orcid.org/0000-0002-1025-1685 cyrne@univates.br

\author{
Júlia Elisabete Barden (iD) \\ Universidade do Vale do Taquari, Brasil \\ http://orcid.org/0000-0002-9818-1844 \\ jbarden@univates.br \\ Fernanda Cristina Wiebusch Sindelar (iD) \\ Universidade do Vale do Taquari, Brasil \\ http://orcid.org/0000-0003-3138-7386 \\ fernanda@univates.br
}

\section{Referencing this:}

BUTTENBENDER, N. B.; FLACH, D. H.; CYRNE, C. C. S.; BARDEN, J. E.; SINDELAR, F. C. W.. Cooperativismo e desenvolvimento: aproximações acerca dos Objetivos de Desenvolvimento Sustentável (ODS). Revista Ibero Americana de Ciências Ambientais, v.12, n.3, p.613-626, 2021. DOI: http://doi.org/10.6008/CBPC2179-6858.2021.003.0049 


\section{INTRODUÇÃO}

O desenvolvimento sustentável tem suas origens em movimentos ambientais que se formaram em meados do século XX, segundo relata Barbosa (2008). A expansão da industrialização e da ocupação de áreas para a exploração mineral e a atividade agrícola, modificou os espaços e culminou na articulação de movimentos que buscam compreender, observar e mitigar os impactos do ser humano no planeta.

Com o amadurecimento das discussões a respeito dos conceitos de sustentabilidade e desenvolvimento sustentável, foi estabelecida em 2015, sob liderança da ONU, a Agenda 2030 para o desenvolvimento sustentável, um plano com 17 Objetivos de Desenvolvimento Sustentável (ODS) e 169 metas, baseadas em quatro dimensões: o desenvolvimento econômico, a inclusão social, a sustentabilidade ambiental e a boa governança.

A Agenda dialoga com iniciativas voltadas à responsabilidade social que tem tido destaque, sobretudo por meio do engajamento das organizações, empresariais ou não, em ações voltadas para o atendimento das demandas sociais que visam melhorias das condições de vida das pessoas e a interação com o meio ambiente.

O cooperativismo carrega a oportunidade de contribuição para o alcance dos ODS, por objetivo ou de forma correlacionada entre eles, pelo seu propósito, a sua forma de atuação e dada a natureza diversificada das atividades das cooperativas. Segundo o Sistema de Organização das Cooperativas do Brasil (OCB), o cooperativismo busca a melhoria de comunidades locais, inclusão financeira, erradicação da pobreza, uso responsável de recursos naturais, entre tantas outras similaridades em relação aos ODS (OCB, 2018). Além do mais, o cooperativismo apresenta crescente relevância dos aspectos sociais e ambientais para com a sociedade de uma maneira geral, ao passo em que se observa o aspecto econômico como facilitador de uma inclusão e redução de desigualdades sociais. Complementarmente, torna-se possível a aproximação dos cooperados desde a geração/produção (assim como em todo o processo de tomada de decisão) até o consumo dos bens e serviços, possibilitando uma gestão estratégica da sustentabilidade da atividade cooperativa.

Assim, o sistema cooperativo, por meio de seus princípios e valores, busca ser um agente ativo no fomento de ações voltadas à comunidade na qual está inserida, além do atendimento das necessidades de seus cooperados. Diante disso, esse estudo tem como objetivo identificar como o cooperativismo participa da construção das condições para o desenvolvimento sustentável, em especial via Agenda 2030.

Desse modo, o presente estudo está estruturado de maneira a apresentar uma fundamentação teórica a respeito da construção do processo de desenvolvimento sustentável e da atividade cooperativa, para a partir disso, relacionar possíveis elementos harmônicos e dissonantes existentes entre os dois. 


\section{REVISÃO TEÓRICA}

\section{Em busca das condições de desenvolvimento sustentável}

A discussão em torno do desenvolvimento não é recente e a proposição de um conceito e de como se caracteriza efetivamente este processo tem sido objeto de estudo e tem evoluído de acordo com o período em que ocorre. A partir dos anos de 1950, o enfoque no desenvolvimento econômico se intensificou, dada a necessidade de crescimento das economias aliado às melhorias nas condições de vida da população.

Na década de 1980, com o Relatório de Brundtland (WCED, 1987), a sustentabilidade passou a pautar o desenvolvimento, apresentando-se inicialmente como uma alternativa para satisfazer as necessidades do presente sem comprometer a capacidade das gerações futuras satisfazerem também suas necessidades.

Desta forma, o termo "desenvolvimento sustentável" surgiu como uma alternativa para a humanidade frente uma crise social e ambiental, a qual caracteriza a situação global a partir da metade do século XX (BARBOSA, 2008). Posteriormente à sua menção na Agenda 21 (documento originário da conferência "Rio 92") e adoção por parte de outras agendas mundiais de desenvolvimento e de direitos humanos, embora observe-se que o conceito de desenvolvimento sustentável é produto de distintas perspectivas (VEIGA, 2005).

Problemas de caráter ambiental (como mudanças climáticas, perda de biodiversidade e esgotamento de recursos naturais), social (vide a empregabilidade da população, acesso à educação, e participação na tomada de decisão nos caminhos que a sociedade irá tomar) e econômico (como é o caso do crescimento econômico, liberdade financeira, dentre outros aspectos) passaram a se destacar como desafios importantes com os quais a sociedade deve lidar, estando contemplados dentro do conceito do triple bottom line (ELKINGTON, 1998), ângulo da sustentabilidade que propõe assegurar a sustentabilidade ambiental, a inclusão social e o desenvolvimento econômico.

A definição acima, usada como base nas discussões acerca do desenvolvimento sustentável, supõe o que alguns autores descrevem como elaborados por dois diferentes "pactos geracionais". O primeiro, um pacto intrageracional, é assim descrito por constituir-se de uma relação entre os membros de uma mesma geração, pelo atendimento das necessidades básicas do presente desta. O segundo pacto, é apresentado pelos autores como intergeracional, ou seja, este seria caracterizado pela relação entre a geração do presente e as gerações futuras. Desta maneira, a proposição fundamental do desenvolvimento sustentável exige que cada constituinte da sociedade venha a contribuir à sua maneira e em suas respectivas áreas de atuação, para tornar efetivos tais pactos intra e intergeracionais.

Os debates em torno de uma sociedade mais sustentável, fez com que diferentes narrativas fossem iniciadas ao longo do tempo, porém, a subjetividade a respeito da temática se colocou como um fator limitador para seu avanço, tanto em relação a um consenso em torno do conceito como em relação a sua operacionalização.

Por outro lado, dada a necessidade e urgência na implantação de ações que mitiguem o baixo desenvolvimento ou até a sua ausência, em 2000 foi estruturada uma proposta clara e concisa, a partir da 
Cúpula do Milênio da ONU (reunião de representantes de 189 países), denominada de Objetivos de Desenvolvimento do Milênio (ODMs). A finalidade dos ODMs era melhorar até 2015 às condições globais de saúde, educação, eliminar a extrema pobreza, além de outros aspectos.

Os ODMs marcaram uma agenda global que visou atingir um padrão mínimo de desenvolvimento na forma de oito objetivos que se constituíram em uma base para que diferentes grupos (países, estados, etc.) manifestassem e descrevessem de uma maneira quantificável seus esforços e avanços contra a pobreza (SACHS, 2012).

Com a consolidação dos ODMs, os aspectos ambientais foram considerados de maneira conjunta sob o objetivo 7, que era apresentado de forma a "Garantir a Sustentabilidade", contudo, posteriormente identificou-se que os ODMs prevaricaram em não direcionar a necessidade de promover padrões sustentáveis de consumo e produção (ONU, 2013).

Projeções futuras, como as oriundas da Conferência do G-20 na ONU, na Coreia do Sul em 2010, onde constituiu-se o Grupo de Trabalho sobre o Desenvolvimento, apresentaram como resultado perspectivas que davam "maior ênfase à inclusão social e à prudência ambiental, mas sem fazer o mesmo com o crescimento econômico" (VEIGA, 2013).

Sachs (2012) sugere que o grande empecilho da aplicação dos então propostos ODMs tenha estado em sua operacionalização para com os países mais pobres, uma vez que sua proposição acenava para uma responsabilidade dos países desenvolvidos para com estes, que não foi cumprida. Em junho de 2012, durante a Rio+20, que tomou base novamente no Rio de Janeiro, foi exposto um relatório que recomendava um grupo de novos objetivos, que tinham como intuito apresentar uma maior proximidade com a realidade presente, substituindo assim os previamente estabelecidos Objetivos de Desenvolvimento do Milênio (SACHS, 2012).

Para Veiga (2013), os ODMs se mostraram bem articulados em sua proposição, a fim de que pudessem ser obtidos significativos avanços durante o período previsto, em questões que vão desde a erradicação da miséria até o combate à AIDS, contudo, estes nada incluem sobre o combate às desigualdades. Para o autor, a relevância dos ODMs nas perspectivas ambientais e econômicas são ainda piores, destacando que "o ambiental nem incorpora questões cruciais como a mudança climática [...] e o econômico não poderia ser mais vago, além de meramente exortativo, ao mencionar uma desejável parceria mundial pelo desenvolvimento" (VEIGA, 2013).

Neste ponto, a discussão começa a tomar forma de maneira a observar este que vem a ser um dos pontos cruciais do desenvolvimento, a questão das desigualdades. O próprio crescimento econômico tem menores benefícios ao não existir uma presença prévia e concomitante da redução das desigualdades.

Segundo Veiga (2013), objetiva-se a redução das desigualdades não apenas em nome do honorável ideal da justiça social, mas sim pela constatação objetiva de que apenas drásticos avanços nas condições de igualdade podem guiar à prosperidade. Os países ricos com menores índices de desigualdade são aqueles que sistematicamente também exibem melhor desempenho em dimensões relevantes para a qualidade de vida de suas populações, considerando fatores como coesão social, dependências químicas, longevidade, mobilidade social e outros. 
Os ODMs foram endereçados tanto para governos quanto para as organizações da sociedade civil, contudo, o balanço geral realizado pelo Programa das Nações Unidas para o Desenvolvimento (PNUD), organização está que promoveu e monitorou a evolução de tais objetivos, ilustra que apesar dos avanços em todas as metas relacionadas ao proposto, os resultados ainda estavam longe do esperado para 2015.

A Rio+20, em 2012, reconheceu a importância dos ODMs como instrumento útil para estabelecer as prioridades nacionais, mobilizar as partes interessadas e os recursos em torno de objetivos comuns. Já em 2013, a Assembleia Geral das Nações Unidas deu início a um grupo de trabalho sobre os Objetivos de Desenvolvimento Sustentável (ODS), almejando o período pós-2015 como espaço de atuação.

Em 2014, esse mesmo grupo de trabalho apresentou um relatório recomendando dezessete objetivos, reunindo um total de 169 metas que devem ser alcançadas até 2030. Finalmente, após a estruturação do grupo de metas e objetivos, constitui-se uma agenda global que considera todos aspectos desenvolvimento econômico, a inclusão social e a sustentabilidade ambiental - somados à prática da boa governança. O grupo de objetivos, que faz frente às metas para a construção do desenvolvimento sustentável, versa sobre um grupo de distintos aspectos conforme a Agenda 2030, e estrutura-se conforme apresenta o quadro 1.

Quadro 1: Objetivos de Desenvolvimento Sustentável (ODS)

Objetivos de Desenvolvimento Sustentável (ODS)
ODS 1. Acabar com a pobreza em todas as suas formas, em todos os lugares;
ODS 2: Acabar com a fome, alcançar a segurança alimentar e melhoria da nutrição e promover a agricultura sustentável;
ODS 3: Assegurar uma vida saudável e promover o bem-estar para todos, em todas as idades;
ODS 4: Assegurar a educação inclusiva e equitativa e de qualidade, e promover oportunidades de aprendizagem ao longo da vida
para todos;
ODS 5: Alcançar a igualdade de gênero e empoderar todas as mulheres e meninas;
ODS 6: Assegurar a disponibilidade e gestão sustentável da água e saneamento para todos;
ODS 7: Assegurar o acesso confiável, sustentável, moderno e a preço acessível à energia para todos;
ODS 8: Promover o crescimento econômico sustentado, inclusivo e sustentável, emprego pleno e produtivo e trabalho decente
para todos;
ODS 9: Construir infraestruturas resilientes, promover a industrialização inclusiva e a sustentável e fomentar a inovação;
ODS 10: Reduzir a desigualdade dentro dos países e entre eles.
ODS 11: Tornar as cidades e os assentamentos humanos inclusivos, seguros, resilientes e sustentáveis;
ODS 12: Assegurar padrões de produção e de consumo sustentáveis;
ODS 13: Tomar medidas urgentes para combater a mudança do clima e seus impactos;
ODS 14: Conservação e uso sustentável dos oceanos, dos mares e dos recursos marinhos para o desenvolvimento sustentável;
ODS 15: Proteger, recuperar e promover o uso sustentável dos ecossistemas terrestres, gerir de forma sustentável as florestas,
combater a desertificação, deter e reverter a degradação da terra e deter a perda de biodiversidade;
ODS 16: Promover sociedades pacíficas e inclusivas para o desenvolvimento sustentável, proporcionar o acesso à justiça para
todos e construir instituições eficazes, responsáveis e inclusivas em todos os níveis;
ODS 17: Fortalecer os meios de implementação e revitalizar a parceria global para o desenvolvimento sustentável.
Fonte: Agenda 2030, ONU (2015).

Os ODS contemplam aspectos não relacionados no grupo antecessor dos ODMs, como a universalização do acesso à energia elétrica, promoção da industrialização inclusiva e sustentável, fomento à inovação e combate à mudança climática e seus impactos e o fomento ao consumo e produção sustentáveis, fator previamente criticado por Veiga (2013).

A delimitação do conceito de consumo e produção sustentáveis, proposto pelo Programa Ambiental das Nações Unidas - UNEP (United Nations Environment Program), descreve tal como sendo o uso de serviços e produtos relacionados que respondem às necessidades básicas e possibilitam uma melhor qualidade de 
vida, mitigando o uso de recursos naturais e de materiais tóxicos, tal qual a redução de emissões de lixo e poluentes sobre o ciclo de vida do serviço ou produto de maneira a não colocar em risco as necessidades das gerações futuras (ONU, 2010).

Apesar de o consumo e a produção sustentáveis não representarem o único caminho para a construção do processo de desenvolvimento sustentável, diferentes estudos sugerem o ODS 12 (objetivo dentro dos ODS constituído com vistas a abordar este aspecto) como sendo um dos eixos fundamentais para o começo desta trajetória (SACHS, 2012; AKENJI et al., 2014; REYERS et al., 2017; BIERMANN et al., 2017; ZANTEN et al., 2018). Em contrapartida aos ODS propostos pela ONU, e em especial ao ODS 12, Akenji et al. (2014) questionam como deve se dar a aproximação deste tema, levantando as duas possibilidades, de que a ideia de consumo e produção sustentável seja observada como um objetivo individual distinto dos demais ou se, então, o mesmo deva ser tomado como base para todos os demais objetivos, sugerindo o termo "Cross-cutting Objective".

Os autores destacam e propõem assim a teoria de que os padrões de consumo e produção determinam o grau de sustentabilidade em cada uma das áreas observadas pelos ODS, sugerindo que a ideia de consumo e produção sustentáveis represente tanto a complexidade quanto a interconexão de todos os demais objetivos, abrindo caminho para o ODS 17, que se propõe a fortalecer os meios de implementação e revitalizar a parceria global para o desenvolvimento sustentável.

Neste contexto, todos os agentes econômicos, dentre eles as cooperativas, são convocados a colaborar para o alcance das metas estipuladas.

\section{O sistema cooperativo}

Existem diferentes estruturas organizacionais no cenário capitalista, dentre estas recebe destaque o cooperativismo. A Organização das Cooperativas Brasileiras (OCB), sugere que o cooperativismo seja entendido como um sistema fundamentado na reunião de pessoas, e não apenas no capital, que visa às necessidades do grupo a parte do lucro, através do desenvolvimento conjunto. Estes fatores fazem do cooperativismo a alternativa socioeconômica que leva ao sucesso, através de seus referenciais de democracia, solidariedade, independência e autonomia (OCB, 2017).

Em adição, Malo (2001) ressalta que se por um lado, as cooperativas são um agrupamento de pessoas, movidas por um objetivo comum que se traduz em uma atividade socioeconômica, por outro lado, uma cooperativa também é uma empresa, inserida na economia de mercado. Assim, faz-se possível que a cooperativa promova o engajamento dos membros nos processos decisórios estratégicos, uma vez que eles são corresponsáveis pela administração e co-proprietários da empresa.

Pinho (2001) ressalta que a cooperativa pode também ser entendida como uma empresa que não busca lucro, pois seu fim imediato é o atendimento das necessidades econômicas de seus usuários, que a criaram com seu próprio esforço, capital e risco. Distingue-se da empresa "capitalista" tradicional ao observar-se que nesta a satisfação das necessidades dos usuários não traduz seu fim imediato em lucro, e sim o faz a multiplicação ou o rendimento do capital investido. 
O autor ainda destaca que a doutrina cooperativa se apresenta como uma proposta de mudança do meio econômico-social, que se concretizará de forma pacífica e gradativa, por meio de cooperativas de múltiplos tipos (PINHO, 2001). Dessa maneira, as economias cooperativas surgem a partir da sinergia entre entidades econômicas autônomas. Segundo sugere Molle (2014), o cooperativismo tem como objetivo a cooperação e a ajuda mútua, por meio da gestão democrática e participativa na busca do desenvolvimento econômico e social da comunidade onde está inserido. Para Bialoskorski Neto (2001), as cooperativas surgem quando diversas unidades econômicas (vide produtores rurais), observam que é mais custoso desenvolver individualmente certa atividade, e organizam-se frente a isso, na forma de uma unidade administrativa, delegando atividades a esta organização.

Neste contexto, diferentes tipologias de cooperativas são adotadas para melhor cumprir sua função de entidade representativa. No ano de 2019, a OCB estabeleceu os 7 ramos do cooperativismo, tomando como base as diferentes áreas em que o movimento atua (OCB, 2020). As denominações atuais dos ramos de atividade foram aprovadas pelo Conselho Diretor da OCB, conforme dispostos a seguir: Agropecuário; de Consumo, de Crédito; Saúde; de Infraestrutura; de Trabalho e Produção de Bens e Serviços; e de Transporte.

Na segunda Assembleia Geral da ICA (International Cooperative Association - organismo máximo do cooperativismo a nível mundial) em 1995 na cidade de Manchester na Inglaterra, foi proposto um conjunto de princípios para nortear o funcionamento das cooperativas. São estes: 1. Adesão livre e voluntária; 2. Gestão democrática; 3. Participação e controle econômico pelos associados; 4. Autonomia e independência; 5. Educação, formação e informação; 6. Intercooperação entre as cooperativas; Compromisso com a comunidade.

Somando-se a isso, a ICA (1995), na mesma assembleia, destacou a existência de um grupo de valores que fundamentam a doutrina cooperativista, ainda que não institucionalmente formalizados como os sete princípios do cooperativismo, mas que somados a estes constituem o que vem a ser compreendido como a nova Declaração de Identidade Cooperativa. Estes valores, pautados na solidariedade, liberdade, democracia, equidade, igualdade, responsabilidade, honestidade, transparência e consciência socioambiental garantem a manutenção do sistema proposto em fundado em 1844 com a primeira Cooperativa em Rochdale, na Inglaterra, ao passo em que se incorporam novos elementos para uma maior interpretação e interconexão com o momento histórico em questão (ICA, 1995).

Em 2011, a Organização das Nações Unidas (ONU, 2011) reconheceu que as cooperativas têm participação ativa no desenvolvimento social e econômico das pessoas, tornando-se assim, um fator importante para o desenvolvimento e contribuindo para a erradicação da pobreza, através da publicação da A/RES/64/136 "As Cooperativas e o Desenvolvimento Social".

\section{METODOLOGIA}

Metodologicamente, o estudo se classifica como uma pesquisa quali-quantitativa, fundamentada em um levantamento bibliográfico e documental de caráter exploratório, visto que o objetivo deste estudo é 
identificar como o cooperativismo participa da construção das condições para o desenvolvimento sustentável, em especial via Agenda 2030.

A etapa qualitativa buscou identificar a relação existente entre os Princípios do Cooperativismo e os ODS e foi baseada em informações constantes das bibliografias vigentes à respeito dos temas, na legislação que regulamenta o sistema cooperativista, assim como, em sites da Organização das Cooperativas do Estado do Rio Grande do Sul - OCERGS, Serviço Nacional de Aprendizagem do Cooperativismo do estado do Rio Grande do Sul - SESCOOP/RS, Organização das Cooperativas Brasileiras - OCB e da Organização das Nações Unidas - ONU, onde apresentam-se os ODS e suas metas. Após análise de cada um dos ODS e respectivas metas a serem alcançadas até 2030 , realizou-se a vinculação destes com os princípios do cooperativismo, apresentados na próxima seção em um quadro síntese juntamente com a análises das vinculações existentes.

A etapa seguinte foi quantitativa e buscou mensurar as ações de responsabilidade social que foram desenvolvidas pelas cooperativas brasileiras, vinculadas ao programa Dia de Cooperar (Dia C), e que contribuem direta ou indiretamente para o alcance dos ODS. Essas informações foram obtidas a partir dos Relatórios do Dia de Cooperar dos anos de 2016, 2017 e 2018, elaborados pelo Sistema OCB. Estes relatórios são disponibilizados anualmente na página da instituição e divulgados em todo o sistema cooperativista, como uma forma de apresentar a contribuição das cooperativas para a sociedade. A partir dos relatórios foi possível quantificar o número de cooperativas e cidades envolvidas nas ações, o número de iniciativas pontuais e de caráter continuado, além do número de voluntários e beneficiados com os projetos. Além disso, estes relatórios apresentam ainda a contribuição das iniciativas desenvolvidas para o alcance dos ODS, demonstrando o comprometimento das cooperativas para o alcance da Agenda 2030 e de condições mais sustentáveis.

\section{RESULTADOS E DISCUSSÃO}

Considera-se que a convergência do processo de construção das condições para um desenvolvimento sustentável com a ação e participação do cooperativismo se dá não apenas em um momento, mas sim em diversos devido à diferentes fatores. Primeiramente, ao tratar-se das cooperativas como sistemas organizacionais próprios, onde os associados podem ser ao mesmo tempo produtores, funcionários e proprietários da cooperativa, existe uma aproximação nítida entre a instituição cooperativa e a comunidade onde está inserida.

Em virtude dessa proximidade, e ilustrando como ponto de partida a relação harmônica que se dá entre o cooperativismo e o desenvolvimento, vê-se no artigo 28 da Lei de no 5.764, de dezembro de 1971 a Lei Geral do Cooperativismo - anterior às primeiras discussões que levaram ao Relatório de Brundtland, que exige das cooperativas, a constituição de um Fundo de Reserva 'destinado a reparar as perdas e atender ao desenvolvimento de suas atividades, constituído com $10 \%$ (dez por cento), pelo menos das sobras líquidas do exercício', onde ao mesmo tempo, demanda-se por meio do FATES, o Fundo de Assistência Técnica, Educacional e Social, a prestação de assistência aos associados, seus familiares e, quando previsto nos 
estatutos, aos empregados da cooperativa, constituído de $5 \%$ (cinco por cento), pelo menos, das sobras líquidas apuradas no exercício.

A Lei do Cooperativismo regimenta e institucionaliza a responsabilidade das cooperativas para com o ambiente onde estas estão inseridas, onde para além de seu envolvimento direto, está ainda é exigida, legalmente, a reverter parcelas dos montantes alcançados em sobras para ações de impacto local. A partir desta Lei, emerge um importante espaço para direcionamento por parte das cooperativas dos investimentos feitos a partir dos fundos da mesma, na participação do processo de construção local do desenvolvimento sustentável.

Do mesmo modo, entende-se uma correlação direta entre estes que são os princípios norteadores do cooperativismo, estabelecidos não apenas como características do movimento, se não como guias de sua existência e atividade - tratando-se, assim, da essência do movimento cooperativista - para com os diversos pontos que constituem os Objetivos de Desenvolvimento Sustentável propostos pela ONU. O quadro 2 sugere a relação de cada princípio do cooperativismo em relação aos ODS.

Quadro 2: Relação dos Princípios do Cooperativismo com os ODS.

\begin{tabular}{|l|l|}
\hline Como se dá a relação entre os Princípios do Cooperativismo e os ODS? \\
\hline Princípios do Cooperativismo & ODS Correspondentes \\
\hline 1- Adesão livre e voluntária & 1,8 e 17. \\
\hline 2- Gestão Democrática & $5,8,10,11$ e 16. \\
\hline 3- Participação econômica & $1,2,8,9,10,11,16$ e 17. \\
\hline $4-$ Autonomia e independência & 8 e 10. \\
\hline $5-$ Educação, Formação e informação & $3,4,8,9,10,12,13,16$ e 17. \\
\hline 6 - Intercooperação & $1,2,3,4,5,6,7,8,9,10,11,12,13,14,15,16$ e 17. \\
\hline $7-$ Interesse pela comunidade & $1,2,3,4,5,6,7,8,9,10,11,12,13,14,15,16$ e 17. \\
\hline
\end{tabular}

O primeiro princípio do cooperativismo, que remete a adesão livre e voluntária às cooperativas, vincula-se aos valores de liberdade e igualdade. Com este viés, se por um lado, nos termos da lei e do estatuto social das cooperativas, o acesso à estas é livre a quem queira cooperar, e, por outro lado, que a manifestação de adesão compete ao próprio interessado, de modo que em hipótese alguma alguém possa ser compelido a ingressar ou permanecer na sociedade estabelecida. Em se considerando os valores de liberdade e igualdade, como já sugerido, e o caráter inclusivo deste princípio torna-se um potencial facilitador do ODS 1, que tem como finalidade acabar com a pobreza em todas as suas formas, em todos os lugares, do ODS 8, que visa promover o crescimento econômico e sustentado, inclusivo e sustentável, emprego pleno e produtivo e trabalho decente para todas e todos - este por sua vez, inerente à todos os 7 princípios cooperativos em função de caracterizar a oportunidade de trabalho decente e crescimento econômico que o cooperativismo representa aos seus associados, e por fim do ODS 10, que direciona-se a reduzir a desigualdade dentro dos países e entre eles.

O ODS 10 também pode ser observado de modo harmônico com todos os princípios cooperativos, em função do caráter socializador que o ramo cooperativo carrega em sua essência, diminuindo as desigualdades existentes entre os entes individuais e coletivos. Por fim, observa-se a relação deste princípio com o ODS 17, que tem como finalidade fortalecer os meios de implementação e revitalizar a parceria global 
para o desenvolvimento sustentável, em função da oportunidade do papel de agente protagonista que as cooperativas desempenham em suas respectivas realidades.

O segundo princípio cooperativo faz referência à gestão democrática, que afirma que as cooperativas são organizações democráticas, controladas pelos seus membros, que participam ativamente na formulação das suas políticas e na tomada de decisões. Em outras palavras, a sociedade cooperativa, no que diz respeito à sua governança, deve orientar-se pelos princípios próprios da democracia, com uma atuação responsável de todos os membros. Este princípio fundamenta-se principalmente nos valores da democracia, da igualdade, da transparência e da responsabilidade. Em função disso, entende-se a existência de uma interação deste princípio em relação ao ODS 5, que visa alcançar a igualdade de gênero e empoderar todas as mulheres e meninas, por meio da representatividade democrática e inclusiva de seus membros, aos ODS 8 e 10 inerentes à todos os princípios, e ao ODS 16, que almeja promover sociedades pacíficas e inclusivas para o desenvolvimento sustentável, proporcionando o acesso à justiça para todos, ao passo em que constroem-se instituições eficazes, responsáveis e inclusivas em todos os níveis. O princípio da gestão democrática representa um forte alicerce para a instauração e manutenção da paz, da justiça e das instituições eficazes.

O terceiro princípio, princípio da participação econômica, aparece como um dos mais fundamentais alicerces da atividade cooperativa, ao passo em que dialoga diretamente com a construção do desenvolvimento sustentável. A aplicação deste princípio torna efetivos os valores propostos no cooperativismo da responsabilidade e da solidariedade. Contempla-se com base no princípio da participação econômica o ODS 1, assim como em outros princípios, o ODS 2 que tem como finalidade acabar com a fome, alcançar a segurança alimentar e melhoria da nutrição e promover a agricultura sustentável, o ODS 9, que almeja construir infraestrutura resiliente, promovendo a industrialização inclusiva e sustentável e fomentar a invocação, os ODS 8 e 10, tal qual nos princípios anteriores, o ODS 11, que visa tornar as cidades e os assentamentos humanos inclusivos, seguros, resilientes e sustentáveis, além dos ODS 16 e 17.

O princípio da autonomia e independência, sustenta que as cooperativas são organizações autônomas, de ajuda mútua, controladas pelos seus membros. Desse modo, faz-se indispensável que a cooperativa seja blindada para evitar a ingerência política ou de qualquer outra força exterior ao meio social (tal como meios sindicais e classistas). O princípio da autonomia e independência pauta-se nos valores da democracia, da transparência e da honestidade, e dessa forma fundamenta o crescimento econômico e a redução das desigualdades, propostos pelos ODS 8 e ODS 10.0 princípio seguinte, que trata da educação, da formação e da informação relaciona-se diretamente com os valores da transparência e responsabilidade, rege pela expansão entre os diferentes públicos e pela sustentabilidade do empreendimento cooperativista, assim como pela conscientização pública sobre as especificidades e apelos do cooperativismo.

Neste sentido, este princípio ampara a busca pelo ODS 3, que visa assegurar uma vida saudável e promover o bem-estar para todos e todas, o ODS 4, que intenta assegurar a educação inclusiva e equitativa e de qualidade, promovendo oportunidades de aprendizagem ao longo da vida para todas e todos, contemplando também os ODS 8, 9, e 10, tal qual os princípios anteriores, o ODS 12 onde o cooperativismo desempenha um potencial ímpar de fomento ao alcance do objetivo de assegurar padrões de produção e de 
consumo sustentáveis, o ODS 13 , que visa tomar medidas urgentes para combater a mudança climática e seus impactos, somando-se ao fomento dos ODS 16 e 17.

O sexto e o sétimo princípios do cooperativismo enquadram-se de modo mais sistêmico com os objetivos de desenvolvimento sustentável, em função de sua capacidade de abrangência. O sexto princípio trata da intercooperação, que para além de ser o caminho para a construção de qualquer mudança em um cenário, tem como fundamento a ideia de que as cooperativas servem de forma mais eficaz aos seus membros e dão mais força ao movimento cooperativo, trabalhando em conjunto, através das estruturas locais, regionais, nacionais e internacionais. Este princípio relaciona-se com o valor da solidariedade, e embasa cada um dos ODS de maneira individual e coletiva, sendo o meio pelo qual pode-se alcançá-los.

Da mesma forma o último princípio, interesse pela comunidade, tem uma aplicação direta que se dá de maneira inter-relacionada com cada um dos ODS, partindo da ideia de que as cooperativas trabalham para o desenvolvimento sustentado e sustentável das comunidades onde atuam através de políticas aprovadas pelos seus próprios membros. Entende-se assim a conexão do princípio do interesse pela comunidade com o valor da responsabilidade socioambiental. Pode-se assim afirmar que enquanto o princípio da intercooperação é o meio para o alcance do desenvolvimento, o princípio do interesse pela comunidade é o fim em si da equação cooperativa.

Além de toda a relação existente entre os pontos que guiam o cooperativismo em suas mais distintas formas de atuação, destacam-se as ações práticas que vêm sendo desempenhadas pelas cooperativas na forma de responsabilidade social em todo o território nacional. No contexto Brasileiro, por intermédio da Organização das Cooperativas Brasileiras (Sistema OCB), consolidou-se em todo o território nacional, a partir de iniciativas menores, o programa Dia de Cooperar (Dia C) que tem como finalidade desenvolver ações de responsabilidade social, colocando em prática os valores e princípios cooperativistas, por meio de ações voluntárias (DIA C, 2019).

Em 2015, o Sistema OCB passou a vincular as iniciativas do Dia C à agenda que contemplou os ODM. Dada a transição desta para a agenda 21, que elencou os ODS, em 2016, o Dia C manteve sua adesão às diretrizes que pretendem construir as condições para um desenvolvimento sustentável. Após 10 anos na primeira iniciativa vinculada ao Dia C, o Dia de Cooperar acontece anualmente em todos os estados brasileiros e conta com ações e participação superior a 1,5 mil iniciativas das cooperativas e uma média de 110 mil voluntários com vistas ao alcance e cumprimento das metas que constituem os ODS. A tabela 1 apresentada informações gerais do Dia C para o período de 2016 a 2018:

Tabela 1: Informações gerais do Dia do Cooperar para o período de 2016 a 2018

\begin{tabular}{llll}
\hline & $\mathbf{2 0 1 6}$ & $\mathbf{2 0 1 7}$ & $\mathbf{2 0 1 8}$ \\
\hline Cooperativas Envolvidas & 1.278 & 1.563 & 1.076 \\
Cidades Envolvidas & 777 & 1.081 & 1.1361 \\
Iniciativas Pontuais & 1.180 & 1.231 & 1.355 \\
Iniciativas Continuadas & 339 & 409 & 509 \\
Voluntários & 86.869 & $120.000^{*}$ & 119.624 \\
Beneficiados & 1.185 .846 & $2.000 .000^{*}$ & 2.242 .259 \\
\hline
\end{tabular}

Onde: * representa valores aproximados

Fonte: Elaborado a partir dos Relatórios do Dia C. 
O Dia C que é um programa de livre-adesão organizado pelo sistema OCB, estrutura a disposição das ações postas em práticas seja de maneira pontual (que acontecem em algum momento específico, como uma ação de reparo da infraestrutura de uma comunidade) ou continuada (como programas longitudinais de educação) de modo que a cooperativa que desenvolve a ação em questão faz a conexão de seu projeto diretamente ao ODS com o qual este projeto está associado, de modo a aproximar ainda mais a conexão existente entre o cooperativismo e o desenvolvimento sustentável. Em ambas as modalidades de iniciativas ocorreu um acréscimo significativo, bem como, uma evolução em relação aos voluntários envolvidos e as pessoas beneficiadas.

Em relação às iniciativas desenvolvidas, os objetivos mais frequentemente contemplados pelas ações de responsabilidade social das cooperativas vinculadas ao programa Dia $C$, foram os ODS 3,4 e 10 , que abordam respectivamente a saúde e o bem-estar (ramo onde está presente a atuação de uma parcela considerável das cooperativas), a educação de qualidade (vide o envolvimento do cooperativismo com os aspectos de educação) e a redução das desigualdades.

Tabela 2: ODS contemplados nos Projetos do Dia C para o período de 2016 a 2018.

\begin{tabular}{llll}
\hline ODS Contemplado & $\mathbf{2 0 1 6}$ & $\mathbf{2 0 1 7}$ & $\mathbf{2 0 1 8}$ \\
\hline $\mathbf{1}$ & 177 & 260 & 286 \\
$\mathbf{2}$ & 130 & 154 & 214 \\
$\mathbf{3}$ & $\mathbf{8 6 0}$ & $\mathbf{9 5 8}$ & $\mathbf{1 . 2 7 3}$ \\
$\mathbf{4}$ & $\mathbf{4 2 1}$ & $\mathbf{4 5 3}$ & 121 \\
$\mathbf{5}$ & 69 & 83 & 51 \\
$\mathbf{6}$ & 36 & 41 & 20 \\
$\mathbf{7}$ & 12 & 17 & 172 \\
$\mathbf{8}$ & 107 & 82 & 26 \\
$\mathbf{9}$ & 9 & 8 & $\mathbf{5 0 5}$ \\
$\mathbf{1 0}$ & $\mathbf{2 8 2}$ & $\mathbf{3 2 4}$ & 275 \\
$\mathbf{1 1}$ & 163 & 232 & 152 \\
$\mathbf{1 2}$ & 96 & 140 & 84 \\
$\mathbf{1 3}$ & 74 & 107 & 45 \\
$\mathbf{1 4}$ & 34 & 52 & 147 \\
$\mathbf{1 6}$ & 82 & 159 & 158 \\
$\mathbf{1 7}$ & 100 & 96 & 187 \\
\hline
\end{tabular}

Fonte: Elaborado a partir dos Relatórios do Dia C de 2018, 2017 e 2016.

Somado às ações do Dia C que dialogam com a perspectiva da educação, o Relatório Expressão do Cooperativismo Gaúcho (OCERGS, 2018) faz referência a outros aspectos onde estão contemplados indiretamente os pontos discutidos pelos ODS. Tomando como base o Índice de Desenvolvimento Socioeconômico (IDESE) de 2015, a OCERGS (2018) aponta para o fato de que "municípios com presença de cooperativas apresentam um IDESE superior àqueles onde o cooperativismo é menos desenvolvido nos níveis de educação e renda", demonstrando mais uma vez uma harmonia da atividade para com os objetivos propostos pela ONU.

\section{CONCLUSÕES}

A partir do contexto analisado, cooperativismo e ODS, sugere-se que a relação do cooperativismo com o a construção do desenvolvimento sustentável se dá em duas grandes frentes. A primeira delas, em decorrência da proximidade de atuação das cooperativas em relação a comunidades onde estão inseridas, 
permitindo uma evidente interação entre estes. Essa proximidade tanto é uma oportunidade para tomadas de decisão e suporte às ações de caráter mais sustentável, como também é um desafio, dado que a cooperativa acaba se tornando, em alguns aspectos, um reflexo dos valores sociais e morais do espaço onde está inserida, podendo se tornar mais um ponto de resistência às mudanças.

Em segundo lugar, e observado mais diretamente neste estudo, os princípios e valores que compõem a atividade cooperativa interagem com os objetivos e metas estabelecidos pela ONU junto aos ODS, como percurso para a construção das condições para um desenvolvimento sustentável,

Os princípios da intercooperação e do interesse pela comunidade, são o meio e o fim do cooperativismo, ao passo em que são também o meio e o fim do desenvolvimento sustentável - apenas com uma característica mais ampla de observação. É somente através da intercooperação que diferentes atores e agentes da sociedade podem desenvolver ações para o bem comum, em vistas à sustentabilidade, e o interesse pela comunidade permeia a ideia de pertencimento e de garantia de possibilidade de continuação de uma sociedade, logo, o interesse pela comunidade almeja a sustentabilidade desta, seja a partir do olhar da cooperativa para sua comunidade, seja para a garantia da sustentabilidade econômica, social e ambiental da sociedade em um modo geral.

Pode-se inferir que as cooperativas brasileiras estão comprometidas com a construção de um cenário mais sustentável e mais colaborativo, endossando assim o proposto na Agenda 2030. Compreende-se que muitos dos princípios e das atitudes cooperativas se enquadram na proposta dos ODS - aliando os aspectos econômicos, sociais, ambientais e de governança - a Aliança Cooperativa Internacional (ACI) e o Sistema OCB aderiram à proposta da ONU desde o lançamento dos ODS em 2015.

As ações de responsabilidade socioambiental desempenhadas pelas cooperativas, vinculadas ou não aos programas do Dia de $C$, também demonstram um trabalho de conscientização destas em relação a importância dos ODS e de se realizar ações de forma unificada para a construção das condições do desenvolvimento sustentável. Através da organização das cooperativas, em caráter internacional através da $\mathrm{ACl}$, nacional por intermédio do Sistema $\mathrm{OCB}$, ou em cada um dos estados através dos respectivos órgãos de administração, faz-se possível o desenvolvimento sustentável, pensando globalmente e agindo localmente.

Faz-se importante, assim, que as cooperativas adotem práticas e diálogos relativos ao tema da sustentabilidade e do desenvolvimento sustentável, dado que estes são intrinsecamente carregados na sua estruturação. Desta maneira, recomenda-se novos estudos que visem observar e caracterizar os impactos socioeconômicos e ambientais das cooperativas em suas comunidades, assim como que apontem e proponham melhorias de gestão em vistas a uma maior sustentabilidade da atividade.

O cooperativismo não só está conectado diretamente com a ideia que fundamenta o desenvolvimento sustentável e com os ODS através de seus princípios e valores, como também desempenha o papel de ator protagonista na construção do processo de desenvolvimento sustentável, servindo de alicerce comunitário para mudanças de paradigmas socioeconômicos e ambientais. Sendo assim, acredita-se ter atingido ao objetivo proposto e de modo a responder que o cooperativismo permite uma aproximação e participa da construção do desenvolvimento sustentável em se considerando a harmonia existente origem 
dos princípios e valores que norteiam o movimento e os objetivos de desenvolvimento sustentável, e ao observar as ações que vêm sendo desenvolvidas de forma prática pelas cooperativas em nível nacional com vistas ao alcance e cumprimento das metas e objetivos que consolidam a agenda mundial de desenvolvimento sustentável.

Recomenda-se, como ponto a ser considerado em estudos futuros, observar como as cooperativas podem aliar as suas práticas de produção e geração de produtos e serviços ao desenvolvimento sustentável, somando-se às ações desenvolvidas por meio da responsabilidade social, para assim consolidar a mudança para um cenário sustentável.

\section{REFERÊNCIAS}

AKENJI, L.; BENGTSSON, M.. Making sustainable consumption and production the core of sustainable development goals. Sustainability, v.6, n.2, p.513-529, 2014. DOI: http://doi.org/10.3390/su6020513

BARBOSA, G. S.. O desafio do desenvolvimento regional. Visões, v.4, n.4, 2008.

BIALOSKORSKI NETO, S.. Cooperative development: changes in brazilian social economy and institutional environment. Review of International Cooperation, v.94, p.59-65, 2001.

BIERMANN, F.; KANIE, N.; KIM, R.. Global governance by goal-setting: the novel approach of the UN sustainable development goals. Current Opinion in Environmental Sustainability, v.26-27, p.26-31 2017

ELKINGTON, J.. Cannibals With Forks: The Triple Bottom Line of 21st Century Business. Stony Creek: New Society Publishers, 1998

ICA. International Coopeartive Association. II Asemblea General de la ACI. Manchester: ICA, 1995.

MALO, M.-C.. La gestion stratégique de la coopérative et de I"association d"économie sociale (1re partie):

L"entrepreneur et son environnement. Revue internationale de l'économie sociale: Recma, n.281, p.84-95, 2001.

MOLLE, A. D.. Melhorias competitivas baseadas na cooperação: um estudo de caso na nova aliança: cooperativa vinícola do Rio Grande do Sul. Dissertação (Mestrado Profissional em Biotecnologia e Gestão Vinícola) Universidade de Caxias do Sul, Caxias do Sul, 2013.

OCB. Organização de Cooperativas do Brasil. O que é cooperativismo?. Brasília: OCB, 2017.

OCB. Organização de Cooperativas do Brasil. Ramos do Cooperativismo. 2020.

OCB. Organização de Cooperativas do Brasil. Relatório de Gestão da Organização da Cooperativas Brasileiras de 2017. Brasília: OCB, 2018

OCERGS. Organização das Cooperativas do Estado do Rio Grande do Sul. A expressão do Cooperativismo Gaúcho 2018. Porto Alegre: Sistema OCERGS SESCOOP/RS, 2018.
ONU. Organização das Nações Unidas No Brasil. Agências da ONU lançam Ano Internacional das Cooperativas 2012. ONU, 2011.

ONU. Organização das Nações Unidas No Brasil. Agenda 2030 para o desenvolvimento sustentável. ONU, 2015.

ONU. Organização das Nações Unidas No Brasil. Agenda 21: Programme of Action for Sustainable Development. New York: ONU, 1992.

ONU. Organização das Nações Unidas No Brasil. Plan of Implementation of the World Summit on Sustainable Development. New York: ONU, 2003.

ONU. Organização das Nações Unidas No Brasil. United Nations Environment Programme (UNEP). ABC of SCP: Clarifying Concepts on Sustainable Consumption and Production. Paris: UNEP, 2010.

PINHO, J. B.. Comunicação em Marketing: princípios da comunicação mercadológica. Campinas: Papirus, 2001.

REYERS, B.; STAFFORD-SMITH, M.; ERB, K.; SCHOLES, R. J.; SELOMANE, O.. Essential variables help to focus sustainable development goals monitoring. Current Opinion in Environmental Sustainability, v.26-27, p.97-105, 2017. DOI: http://doi.org/10.1016/i.cosust.2017.05.003

SACHS, J.. From millennium development goals to sustainable development goals. Viewpoint, v.379, n.9832, p.2.206-2.211, 2012

VEIGA, J. E.. A desgovernança mundial da Sustentabilidade. São Paulo: 34, 2013.

VEIGA, J. E.. Cidades Imaginárias: o Brasil é menos urbano do que se calcula. Campinas: Unicamp, 2005.

WCED. Our common Future. Oxford: Oxford University Press, 1987.

ZANTEN, H. H. E. V.; HERRERO, M.; HAL, O. V.; RÖÖS, E.; MULLER, A.; GARNETT, T.; GERBER, P. J.; SCHADER, C.; BOER, I. J. M.. Definig a land boundary for sustainable livestock consumption. Global Change Biology, v.24, n.9, p.4.1854.194, 2018. DOI: http://doi.org/10.1111/gcb.14321

A CBPC - Companhia Brasileira de Produção Científica (CNPJ: 11.221.422/0001-03) detém os direitos materiais desta publicação. Os direitos referem-se à publicação do trabalho em qualquer parte do mundo, incluindo os direitos às renovações, expansões e disseminações da contribuição, bem como outros direitos subsidiários. Todos os trabalhos publicados eletronicamente poderão posteriormente ser publicados em coletâneas impressas sob coordenação da Sustenere Publishing, da Companhia Brasileira de Produção Científica e seus parceiros autorizados. Os (as) autores (as) preservam os direitos autorais, mas não têm permissão para a publicação da contribuição em outro meio, impresso ou digital, em português ou em tradução. 